\title{
Compassionate and respectful maternity care during facility based child birth and women's intent to use maternity service in Bahir Dar, Ethiopia
}

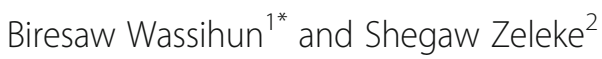

\begin{abstract}
Background: Compassionate and respectful maternity care is one of the most important facilitating factors to increase access to skilled maternity care. Disrespect and abuse is a violation of human rights and is the main hindering factor preventing skilled birth utilization versus other more commonly recognized deterrents such as financial and geographical obstacles.

Methods: Institution based cross-sectional study design was conducted. A structured and pre-tested interviewer administered questionnaire was used to collect the data from 284 study participants. Study participant were selected using a systematic random sampling technique by allocating a proportion to each health facility. The data were entered with Epi data version 3.1statistical software and exported to Statistical Package for Social Sciences version 22.0 for further analysis. Both bivariate and multivariate logistic regression analysis were performed to identify associated factors. $P$ values $<0.05$ with $95 \%$ confidence level were used to declare statistical significance.

Result: A total of 284 respondents participated in the study with a response rate of $100 \%$.The overall prevalence of respectful maternity care experienced was $57 \%$.The multivariable analysis indicated that respondents who live in a rural area $[A O R=6.49(95 \% C l ; 2.59,16.21)]$, experience a caesarian birth $[A O R=4.52(95 \% \mathrm{Cl} ; 1.64,12.42)]$, have complications during delivery $[\mathrm{AOR}=2.38(95 \% \mathrm{Cl} ; 1.28,4.45)]$ and future intention to use health facility $[\mathrm{AOR}=3$. $57(95 \% \mathrm{Cl} ; 1.81,7.07)]$ were some of the factors associated with experiencing disrespect and abuse.

Conclusion: This study showed a high prevalence of disrespect and abuse during facility child birth in Bahir Dar town, Ethiopia as compared to previous literature. Being from rural area, having complications during delivery and mothers who gave birth through caesarian section were more likely to be exposed to disrespect and abuse than other women. Mistreatment of mothers during facility child birth is a health facility failure, a violation of women's rights and a notable barrier for institutional delivery.
\end{abstract}

Keywords: Compassionate, Respectful, Disrespect, Abuse, Child birth, Ethiopia

\footnotetext{
* Correspondence: bireswas@gmail.com

${ }^{1}$ College of Medicine and Health Sciences, Arba Minch University, Arba

Minch, Ethiopia

Full list of author information is available at the end of the article
}

(c) The Author(s). 2018 Open Access This article is distributed under the terms of the Creative Commons Attribution 4.0 International License (http://creativecommons.org/licenses/by/4.0/) which permits unrestricted use, distribution, and reproduction in any medium, provided you give appropriate credit to the original author(s) and the source, provide a link to the Creative Commons license, and indicate if changes were made. The Creative Commons Public Domain Dedication waiver (http://creativecommons.org/publicdomain/zero/1.0/) applies to the data made available in this article, unless otherwise stated. 


\section{Backgroud}

Child birth is a special moment for parents, families and communities but can also be a time of intense vulnerability for women to be exposed to disrespectful and abusive behavior while at the health facilities. If mothers do not receive what they perceive as compassionate and respectful maternity care during facility based child birth their intention to use facility based maternity services will be reduced [1].

The concept of "safe motherhood" is usually restricted to physical safety, but childbearing is also an important passage from woman to mother, with deep personal and cultural significance for a woman and her family. Because motherhood is specific to women, issues of gender equity and gender violence are also at the core of maternity care [2].

In recent years advocacy for skilled birth attendance has increased and has become the single most important intervention suggested to decrease maternal mortality and morbidity. However, client satisfaction with such care, which is an important element of quality care, which has the potential to influences effectiveness of care, has not been given enough attention [2, 3].

Problems related to maternal provider behaviors and attitudes are a major barrier when compared to any other geographical or financial barriers to utilization of skilled childbirth care [4].

Advancing compassionate and respectful maternity care is critical in order to increase facility based child birth and ensure effective implementation of women's rights and women-centered approaches in maternal health services. In fact efforts to increase the use of facility based maternity care service in low resources countries are unlikely to achieve desired gains without improving the quality of care and focusing on women's experience of care [5].

Despite advances in maternal health outcomes, ensuring that women have skilled and respectful care during delivery remains a challenge. In many countries, women are mistreated when delivering in health facilities and unable to make choices or follow practices that allow them to be in control of their own experience [6]. In addition, health systems are underequipped and health workers are not satisfied due to inadequate pay, lack of infrastructure, or insufficient staff and supplies; staff may also not receive guidance, support or supervision facilitating the provision of respectful maternity care [7].

According to the WHO statement on the prevention and elimination of disrespect and abuse of women during facility-based childbirth and the White Ribbon Alliance charter, respectful maternal care refers to "the right of every woman to the highest attainable standard of health, which includes the right to dignified, respectful health care at all health systems around the world of childbearing woman throughout her pregnancy, during labour and delivery, and post natal period" $[1,8]$. Maternal morbidity and mortality has continued to be a public health problem globally as evidenced by high maternal morbidity and mortality [9]. Globally in 2015, an estimated 303,000 women have lost their lives due to easily preventable pregnancy and childbirth related complications, $99 \%$ of which were in low income countries. In this figure, sub- Saharan Africa alone was accountable for $66 \%$ of the deaths [10].

Ethiopia has one of the highest maternal mortality rates globally (MMR) of 412 maternal deaths per 100,000 live births [11].

In countries where more than $80 \%$ of births are attended by trained health personnel, the rate of maternal mortality is less than 200 per 100,000 live births. Thus one of the strategies designed to decrease maternal morbidity and mortality was to increase maternity up take with skilled health care providers [9, 12, 13].

The proportion of women who are giving birth at health institutions with trained birth attendants in Ethiopia is not more than 28\%. [11] . Multiple studies have examined reasons for failing to use skilled services during delivery. However, there is inadequate research linking the role of disrespect and abuse of women during facility based deliveries and decreased utilization of maternity services. Disrespect and abuse during childbirth, which is a violation of a universal human right that is due to every childbearing woman in every health system, is common throughout the world and can occur at the level of interaction between the woman and provider leading to low intake of maternity service [14-16].

Despite the problem, little research has been conducted in Ethiopia with regard to the status of disrespect and abuse during facility-based childbirth. Therefore this study aimed at assessing the status of compassionate and respectful maternity care and associated factors in health facility-based childbirth in Bahir Dar town.

\section{Methods}

Study area

This study was conducted in public health facilities in Bahir Dar town. Bahir Dar is located in North Western part of Ethiopia, in Amhara National Regional State, at a distance of $565 \mathrm{~km}$ from Addis Ababa. The total population of the town is 290,437of which 142,068 are males and 148,369 are female. In Bahir, Dare town there are 10 public health centers and two public hospitals and two private health institutions. The study was conducted in five public health facilities; four health centers and one referral hospital.

\section{Study design and period}

Institution based cross-sectional study was conducted from Feb 2- April 26-2017. 


\section{Population}

Mothers who gave birth in Bahir Dar tow health facilities.

\section{Sample size determination}

A single proportion formula was used to estimate the sample size required for the study. The sample size calculation assumed the proportion (p) estimated level of respectful and abuse free maternity care $21.4 \%$ [17]. Adding non-response rate of $10 \%$ and considering the assumption of $95 \%$ confidence level, $5 \%$ margin of error the final sample size was 284 mothers.

\section{Sampling procedure}

In this study area there are ten public health centers and two public hospitals (one referral hospital and second general hospital). Four public health centers and one referral hospital was randomly selected. The allocation of the sample to health facilities was made proportionally based on the average number of clients who received childbirth services at each facility in the month preceding the data collection period. Felege-Hiwot Referral Hospital 129: Bahir Dar Health center 48: Han Health center 29: Tis-Abay Health center 45 and Shinbut Health center 33. Individual participants in each of the health facilities were selected by systematic random sampling during the data collection period until the required sample size at each health facility was obtained. The sampling interval $\mathrm{k}=3$ was calculated by dividing the source population to the total sample size and this interval was used in all health facility to select study participants. The first client was selected by simple random sampling among the first three maternity care users in the sampling frame.

\section{Operational definition}

Respectful maternity care (RMC) A universal human right that is due to every childbearing woman in every health system around the world in which the maternity care is expanded beyond the prevention of morbidity or mortality to encompass respect for women's basic human rights, including respect for women's autonomy, dignity, feelings, choices, and preferences, such as having a companion wherever possible [18].

\section{Data collection tool}

The data collection method that was used in this study was face to face interviews using a structured questionnaire. The English version questionnaire was translated into local language Amharic to obtain data from the study participants and to ensure clarity of its content. Then the Amharic version was transcribed back to English version to check for consistency. It was prepared by the principal investigator based on literature reviews, and from Maternal and Child Health Integrated Program (MCHIP) as part of their respectful maternity care tool kit [3]. The questionnaire was designed to obtain information on socio demographic-characteristics and factors associated with disrespect and abuse. The instrument was pretested for its reliability. The content validity of the questionnaire was reviewed by experienced public health professionals.

\section{Data collection procedure and quality control}

Before actual data collection occurred two day training was provided for data collectors and the supervisor about techniques of data collection and briefed on each questions included in the data collection tool. Pretest was done on $10 \%$ (28) of mothers receiving care in a health center that was not included in the study prior to the actual study period. After pre-testing the questionnaire, Cronbatch's Alpha was calculated by using SPSS window version 22.0 to test internal consistency (reliability) of the item and Cronbatch's Alpha greater than 0.7 was considered as reliable. Data were collected by trained midwives and nurses. During data collection regular supervision was done by the supervisors.

\section{Data processing and analysis}

First the collected data were checked manually for completion and any incomplete or misfiled questions. The data were cleaned and stored for consistency, entered into Epi Data version 3.1 software then exported to statistical package for social sciences (SPSS) version 22.0 software for analysis. The accuracy of the data entry was checked by double data entry. Any errors identified during data entry were corrected by reviewing the original completed questionnaire. Descriptive statistics were done and presented using tables and figures. Initially, bivariate logistic regression was carried out to see the association of each of the independent variables with the outcome variable. Thereafter, the multivariable logistic regression method was used. The variables that were not significant in the bivariate logistic regression were not considered in the multiple regression analysis. P- Value of $<0.05$ and $95 \%$ confidence level was used as a difference of statistical significance. Finally, results were compiled and presented using tables, graphs, and text.

\section{Results}

Socio-demographic characteristics of respondent

From a total of 284 respondents who were invited for interview all consented to participate in the study giving a response rate of $(100 \%)$. Mean age of the respondents was $28.3(\mathrm{SD} \pm 6.5)$ years with a minimum and maximum age of 15 and 46 respectively. Almost all of the study participants 230 (81.0\%) were from the Amhara ethnic group and 211 (74.3\%) were Orthodox Christianity 
religion followers. Regarding marital status of the mother, $259(91.2 \%)$ of them were married. Out of the total respondents $145(51.1 \%)$ of them had a monthly family

Table 1 Socio demographic characteristics of respondents in Bahir Dar town public health facility, North West Ethiopia, 2017 $(n=284)$

\begin{tabular}{|c|c|c|}
\hline Variables & Frequency & Percentage \\
\hline \multicolumn{3}{|l|}{ Age } \\
\hline 15-19 & 4 & 1.4 \\
\hline $20-24$ & 130 & 45.8 \\
\hline $25-29$ & 28 & 9.9 \\
\hline $30-34$ & 91 & 32.0 \\
\hline 35 and above & 31 & 10.9 \\
\hline \multicolumn{3}{|l|}{ Occupation } \\
\hline House wife & 57 & 20.1 \\
\hline Government employee & 182 & 64.1 \\
\hline Private business & 45 & 15.8 \\
\hline \multicolumn{3}{|l|}{ Ethnicity } \\
\hline Amhara & 230 & 81.0 \\
\hline Oromo & 14 & 4.9 \\
\hline Awi & 25 & 8.8 \\
\hline Tigira & 12 & 4.2 \\
\hline Others & 3 & 1.1 \\
\hline \multicolumn{3}{|l|}{ Religion } \\
\hline Orthodox & 212 & 74.7 \\
\hline Protestant & 24 & 8.8 \\
\hline Muslim & 48 & 16.9 \\
\hline \multicolumn{3}{|l|}{ Marital status } \\
\hline Married & 259 & 91.2 \\
\hline Divorced & 10 & 3.5 \\
\hline Single & 11 & 3.9 \\
\hline Widowed & 2 & 0.7 \\
\hline Separated & 2 & 0.7 \\
\hline \multicolumn{3}{|l|}{ Mothers educational status } \\
\hline Illiterate & 13 & 4.6 \\
\hline Read and write & 23 & 8.1 \\
\hline Elementary school (grade 1-4) & 29 & 10.2 \\
\hline Secondary school (grade 5-8) & 23 & 8.1 \\
\hline High school (grade 9-12) & 13 & 4.6 \\
\hline Diploma and above & 183 & 64.5 \\
\hline \multicolumn{3}{|l|}{ Family monthly income } \\
\hline$<3000$ & 145 & 51.1 \\
\hline$\geq 3000$ & 139 & 48.9 \\
\hline \multicolumn{3}{|l|}{ Median income 3000} \\
\hline \multicolumn{3}{|l|}{ Residence } \\
\hline Urban & 235 & 82.7 \\
\hline Rural & 49 & 17.3 \\
\hline
\end{tabular}

income $<3000$ Ethiopian birr. Almost all of the respondents $250(88.0 \%)$ were not able to pay for any medical services. Of the total respondents 235 (82.7) were urban residents (Table 1).

Table 2 .Obstetric characteristics of respondents in Bahir Dar town public health facility, North West Ethiopia, $2017(n=284)$

\begin{tabular}{|c|c|c|}
\hline Variables & Frequency & Percentage \\
\hline \multicolumn{3}{|l|}{ Gravidity } \\
\hline Prima- gravid & 31 & 10.9 \\
\hline Multi gravid & 253 & 89.1 \\
\hline \multicolumn{3}{|l|}{ Parity } \\
\hline Primparous & 29 & 10.2 \\
\hline Multiparous & 253 & 89.8 \\
\hline \multicolumn{3}{|c|}{ Pregnancy wanted/planned } \\
\hline Yes & 238 & 83.8 \\
\hline No & 46 & 16.2 \\
\hline \multicolumn{3}{|l|}{ Antenatal care } \\
\hline Yes & 267 & 94.0 \\
\hline No & 17 & 6.0 \\
\hline \multicolumn{3}{|c|}{ Place of Antenatal care } \\
\hline Public health facility & 222 & 78.2 \\
\hline Private health facility & 45 & 16.9 \\
\hline \multicolumn{3}{|c|}{ History of health facility delivery } \\
\hline Yes & 260 & 91.5 \\
\hline No & 24 & 8.5 \\
\hline \multicolumn{3}{|c|}{ Current mode of delivery } \\
\hline Vaginal & 151 & 53.2 \\
\hline Vacuum /forceps & 92 & 32.4 \\
\hline Cesarean section & 41 & 14.4 \\
\hline \multicolumn{3}{|c|}{ Sex of health care provider conducting delivery } \\
\hline Male & 140 & 50.7 \\
\hline Female & 144 & 49.3 \\
\hline \multicolumn{3}{|l|}{ Having complication } \\
\hline Yes & 116 & 40.8 \\
\hline No & 168 & 59.2 \\
\hline \multicolumn{3}{|c|}{ Stayed in health facility } \\
\hline Yes & 239 & 84.2 \\
\hline No & 45 & 15.8 \\
\hline \multicolumn{3}{|c|}{$\begin{array}{l}\text { Do you have intention to give birth in health } \\
\text { facility? }\end{array}$} \\
\hline Yes & 189 & 66.0 \\
\hline No & 97 & 34.0 \\
\hline \multicolumn{3}{|l|}{ If no, why? } \\
\hline I am not satisfied & 73 & 75.3 \\
\hline Home is better & 19 & 19.6 \\
\hline No reason & 5 & 5.2 \\
\hline
\end{tabular}




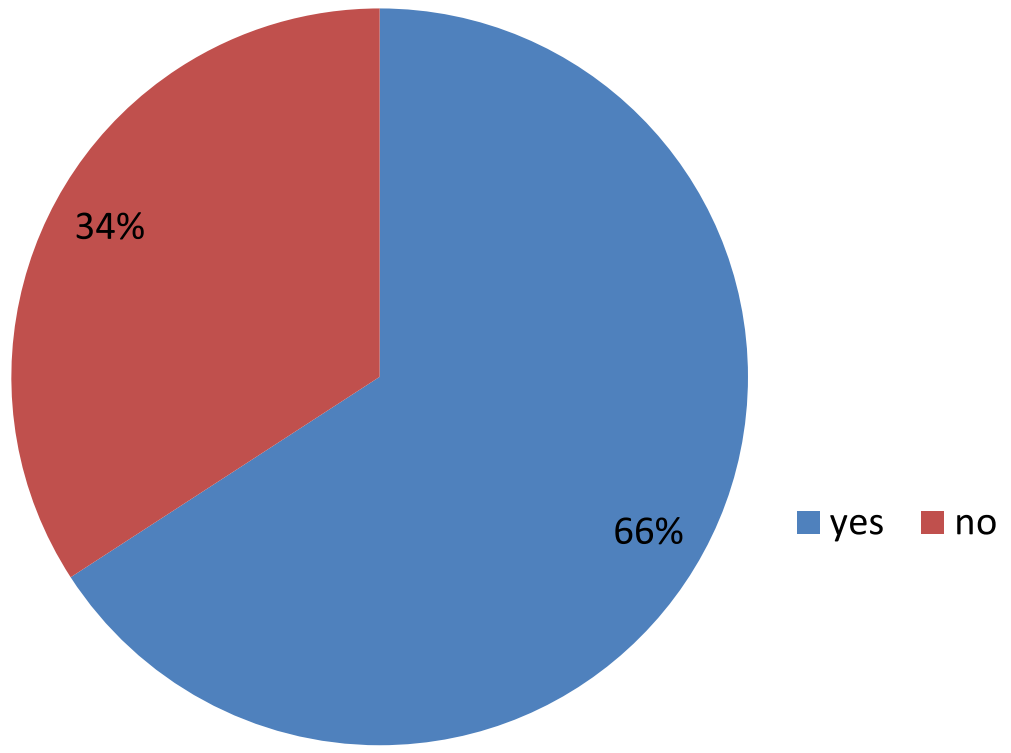

Fig. 1 Intention of respondents to give birth in Bahir Dar town public health facility, North West Ethiopia, 2017

\section{Obstetric history of respondents}

From the total of 284 respondents 267 (94.0\%) had a history of antenatal care follow up. The majority of mothers 253 (89.1) were multigravida and 255 (89.8) were multipara. Almost all of the respondents 260 (91.5\%) of the multiparas had previously given birth in institutions. Among respondents 151 (53.2) were gave birth vaginally and 41 (14.4) were gave birth by caesarian section. From the total respondents 97 (32.4\%) had no intention of giving birth in a health facility in a future birth. The main reasons for not giving birth in a health facilities was a lack of satisfaction during their current labour and delivery 73 (25.7\%) followed by home preference 19 (6.7\%) (Table 2, Fig. 1).

\section{Category of respectful maternity care (RMC)}

The most common category of respectful maternity care identified by women in this study was providing discrimination free care $32.4 \%$ followed by providing friendly care $26.1 \%$ (Table 3, Fig. 2).

Table 3 Categories and types of respectfully maternity care reported by mothers during childbirth, in Bahir Dar town public health facility, North West Ethiopia, $2017(n=284)$

\begin{tabular}{|c|c|c|c|}
\hline Category of RMC & Types of RMC & Yes (\%) & No (\%) \\
\hline \multirow[t]{7}{*}{ Friendly care } & I felt that health workers cared for me with a kind approach & 196(69.0) & $89(31.0)$ \\
\hline & The health workers treated me in a friendly manner & 194(68.3) & $90(31.7)$ \\
\hline & The HWs was talking positively about pain and relief & 198(69.7) & $86(30.3)$ \\
\hline & The health worker showed his/her concern and empathy & 198(69.7) & $86(30.3)$ \\
\hline & All HWs treated me with respect as an individual & 195(68.7) & $89(31.3)$ \\
\hline & The HWs speak to me in a language that I can understand & 194(68.3) & $90(31.7)$ \\
\hline & The health provider called me by my name & 192(67.6) & $92(32.4)$ \\
\hline \multirow[t]{3}{*}{ Abuse free care } & The health worker responded to my needs whether or not I asked & 198(69.7) & $86(30.3)$ \\
\hline & The health provider slapped me during delivery for different reasons & $98(34.5)$ & 186(65.5) \\
\hline & The health workers shouted at me because I haven't done what I was told to do & $95(33.5)$ & 189(66.5) \\
\hline \multirow[t]{3}{*}{ Timely care } & I was kept waiting for a long time before receiving service & $92(32.4)$ & 192(67.6) \\
\hline & I was allowed to practice cultural rituals in the facility & $92(32.4)$ & 192(67.6) \\
\hline & Service provision was delayed due to the health facilities internal problem & $89(31.3)$ & 195(68.7) \\
\hline \multirow[t]{2}{*}{ Discrimination free care } & Some of the health workers do not treated me well because of some personal attribute & $92(32.4)$ & 192(67.6) \\
\hline & Some HWs insulted me and my companions due to my personal attributes & $89(31.3)$ & 195(68.7) \\
\hline
\end{tabular}

* RMC stands for respectful maternity care. HWs* stands for health care workers 


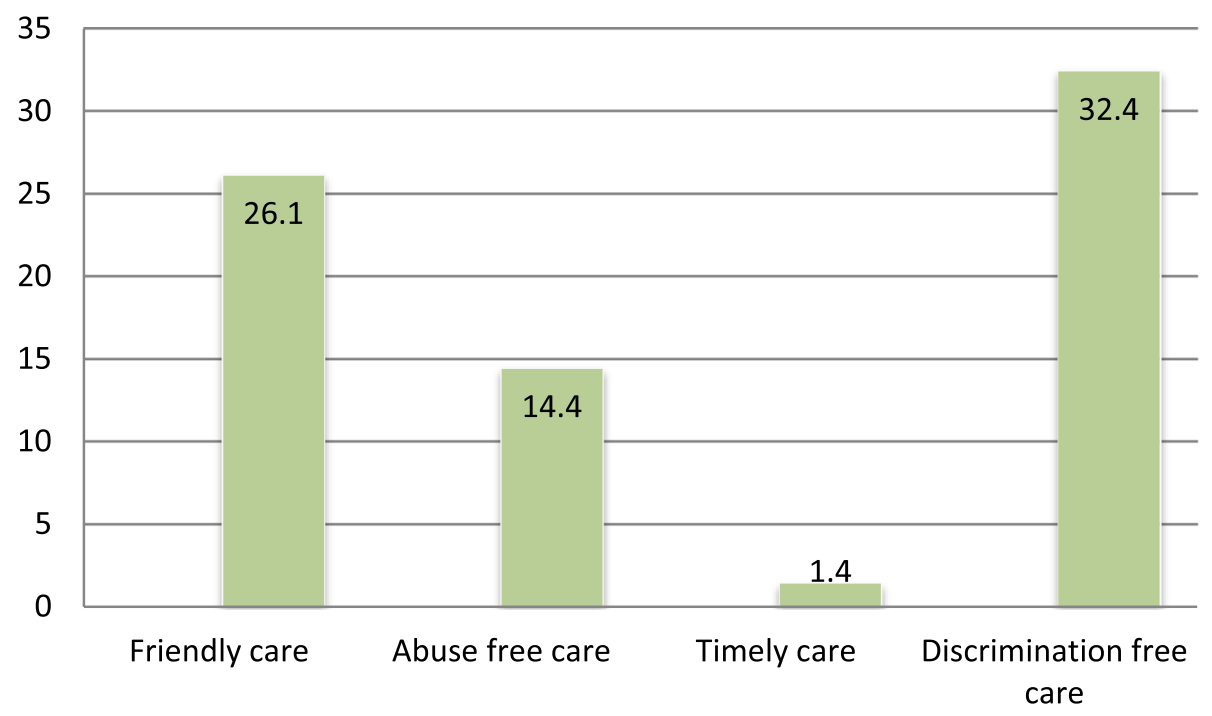

Fig. 2 Prevalence of each category of respectful maternity care in Bahir Dar town public health facility, North West Ethiopia, 2017

Prevalence of compassionate and respectful maternity care Out of the 284 respondents interviewed 163(57\%) experienced compassionate and respectful maternity care while $121(43 \%)$ reported having experienced at least one form of disrespect and abuse during facility based childbirth (Fig. 3).

\section{Factors associated with compassionate and respectful maternity care}

The result of multiple logistic regression analysis showed that respondent residency, mode of delivery, time of delivery, complication during delivery, family monthly income and intention to give birth in a health facility were some of the factors associated with disrespect and abuse at
$P$-value $<0.05$. Respondents who were from rural area were 6.49 times more likely to report disrespect and abuse than urban residents $[\mathrm{AOR}=6.49(95 \% \mathrm{CI} ; 2.59,16.21)]$. Similarly respondents who gave birth through caesarian section were 4.52 times more likely to experience disrespect and abuse than those respondents who gave birth through vaginal delivery $[\mathrm{AOR}=4.52(95 \% \mathrm{CI} ; 1.64,12.42)]$. Respondents who were facing complication during labor and delivery were 2.38 times more likely to experience disrespect and abuse than those respondents who did not face complications $[\mathrm{AOR}=2.38(95 \% \mathrm{CI} ; 1.28,4.45)]$. Respondents who did not intend to give birth in a health facility in the future were 3.57 times more likely to have reported

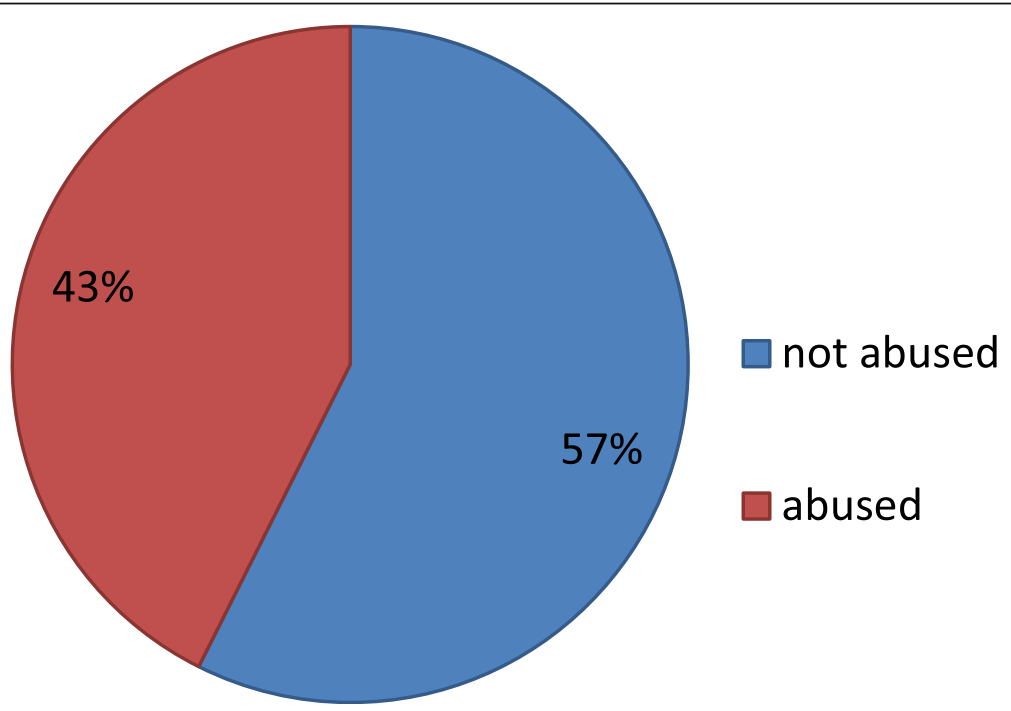

Fig. 3 Prevalence of compassionate and respectful maternity care during facility based child birth in Bahir Dar town, public health Facilities, North West Ethiopia, 2017 
experiencing disrespect and abuse than those respondents planning to do so $[\mathrm{AOR}=3.57(95 \% \mathrm{CI}$; 1.81 , 7.07)] (Table 4).

\section{Discussion}

This study investigated the prevalence and factors associated with compassionate and respectful maternity care during facility-based childbirth in Bahir Dar town at the facility level. This study revealed that the prevalence of compassionate and respectful maternity care was reported by $57 \%$ of women, with abusive maternity care reported by $43 \%$. This proportion is higher than that in a study conducted in Kenya which showed that $20 \%$ of women reported any form of disrespect and abuse during child birth [19]. The considerable difference may be due to socio-cultural and socio-economic. It may also be due to differences in staff training and organization of healthcare. However, the proportion women reporting abuse in this study is lower than a study conducted in Enugu in Nigeria where 98\% of the

Table 4 Bivariate and multivariate logistic regression analysis of disrespect and abuse and its explanatory variables in Bahir Dar town public health facility $(n=284)$

\begin{tabular}{|c|c|c|c|c|}
\hline \multirow{2}{*}{$\frac{\text { Variables }}{\text { Age }}$} & \multicolumn{2}{|c|}{ Experience of $D$ and $A$ Yes No } & \multirow[t]{2}{*}{ COR $(95 \% \mathrm{Cl})$} & \multirow[t]{2}{*}{ AOR $(95 \% \mathrm{Cl})$} \\
\hline & & & & \\
\hline $15-24$ & 65 & 69 & 1 & 1 \\
\hline $25-34$ & 46 & 73 & $0.66(0.41-1.10)$ & $0.84(0.44-1.63)$ \\
\hline 35 and above & 10 & 21 & $0.50(0.22-1.15)$ & $0.72(0.25-2.07)$ \\
\hline \multicolumn{5}{|l|}{ Educational status } \\
\hline No formal education & 22 & 14 & $2.43(1.17-5.03)^{*}$ & $0 . .39(0.64-0.24)$ \\
\hline Primary & 22 & 30 & $1.13-(0.61-2.11)$ & $0.84(0.31-1.89)$ \\
\hline Secondary and above & 77 & 119 & 1 & \\
\hline \multicolumn{5}{|l|}{ Family monthly income } \\
\hline$<3000$ & 76 & 69 & $2.3(1.42-3.73)^{*}$ & $0.90(0.46-1.75)$ \\
\hline$\geq 3000$ & 45 & 94 & 1 & 1 \\
\hline \multicolumn{5}{|l|}{ Resident } \\
\hline Urban & 82 & 153 & 1 & 1 \\
\hline rural & 39 & 10 & $7.23(3.45-15.32)^{*}$ & $6.49(2.59-16.21)^{*}$ \\
\hline \multicolumn{5}{|l|}{ Gravidity } \\
\hline Prima- gravid & 19 & 12 & $2.34(1.09-5.04)^{*}$ & $2.06(0.80-5.28)$ \\
\hline Multi- gravid & 102 & 151 & 1 & 1 \\
\hline \multicolumn{5}{|c|}{ Pregnancy planned and wanted } \\
\hline Yes & 84 & 154 & 1 & 1 \\
\hline No & 37 & 9 & $7.54(3.47-16.37)^{*}$ & $0.24(0.09-0.62)$ \\
\hline \multicolumn{5}{|l|}{ Mode of delivery } \\
\hline Vaginal & 63 & 88 & 1 & 1 \\
\hline Vacuum/forceps & 27 & 65 & $0.58(0.33-1.00)$ & $0.44(0.19-1.01)$ \\
\hline Caesarian section & 31 & 10 & $4.33(1.98-9.47)^{*}$ & $4.52(1.64-12.42)^{*}$ \\
\hline \multicolumn{5}{|l|}{ Time of delivery } \\
\hline Day time & 76 & 82 & $1.66(1.03-2.69)^{*}$ & $2.16(1.04-4.49)^{*}$ \\
\hline Night time & 45 & 81 & 1 & 1 \\
\hline \multicolumn{5}{|c|}{ Facing complication during labour and delivery } \\
\hline Yes & 68 & 48 & $3.07(1.88-5.03)^{*}$ & $2.38(1.28-4.45)^{*}$ \\
\hline No & 53 & 115 & 1 & 1 \\
\hline \multicolumn{5}{|c|}{ Intention to give birth in health facility } \\
\hline Yes & 52 & 115 & 1 & 1 \\
\hline No & 69 & 28 & $6.39(3.72-11.02)^{*}$ & $3.57(1.81-7.07)^{*}$ \\
\hline
\end{tabular}

$\mathrm{D}$ and $\mathrm{A}$ remind as disrespect and abuse, ${ }^{*}$ remands as statically significant at $\mathrm{p}$-value of $<0.05$ 
women have reported that they have had at least one instance of abuse during the course of childbirth [20]. The differences may also be due to the study period selected and the relatively small sample size in this study. The results of this study also show a higher level of abusive maternity care compared with data collected in Tanzania where the frequency of any abusive or disrespectful treatment during childbirth was 19\% [21]. The considerable difference may be due to socio-cultural and socio-economic poupulation difference. In this study $34.5 \%$ of respondents reported that a health care provider slapped them during childbirth compared with a similar proportion in Nigerian study which showed that $35.7 \%$ of women reported slapping during childbirth at health facilities [19]. In this study negligent care was reported by $30.3 \%$ of women which is markedly higher than the study conducted in Tanzania with only $7.9 \%$ reporting negligent care [20]. Respondents who gave birth by caesarian section were four times more likely to be disrespected and abused than respondents who had gave birth through vaginal delivery perhaps it is due to staff work load and attitude of health care provider. The results of this study show that the prevalence of disrespect and abuse at $43 \%$ is lower than that reported in Addis Ababa, Ethiopia where the comparable figure for facility-based childbirth was $76.8 \%$ [17].The discrepancy may be due to services improvement. Similarly, the overall prevalence of compassionate and respectful maternity care was $57 \%$ which is notably higher than the $21.4 \%$ reported in the study conducted in Addis Ababa [17]. The study also revealed that respondents who were residents of rural areas were six times more likely to experience disrespect and abuse than urban residents. Over all in this study the prevalence of discrimination- free care was experienced by only a third of women, with friendly care reported by a quarter. Income level also made a difference, with respondents in this study having a low family monthly income of $<3000$ Ethiopian birr being twice as likely to be disrespected and abused as respondents with a higher family monthly income. This finding is in line with the study conducted in Addis Ababa which showed that respondents with low family monthly income were significantly more likely to report disrespect and abuse [17]. Respondents who have no intention to give birth in a health facilities were six time more likely to report disrespect and abuse than respondents who have the intention to give birth in a health facilities. The finding of this study showed that the prevalence of disrespect and abuse is high. To reduce this high prevalence all stakeholders who were working to reduce maternal and child mortality must be involved to promoting respectful maternity care for all child bearing mothers. In addition to this strengthening responsibility through legal redress, citizen involvement on hospital administration boards, client health care charters, improving the quality of the work environment for providers, training and introduction of care standards is very important to promote compassionate and respectful maternity care.

\section{Conclusions}

The results of this study show that the prevalence of disrespect and abuse during childbirth was $43 \%$ among the women studied. Abuse of mothers during facility child birth is a health facility failure and a violation of women's rights as well as an important barrier to women seeking institutional delivery. Independent factors identified that increased disrespect and abuse included low family monthly income, rural residency, complications during delivery, caesarian birth and intention not to use maternity service. Therefore, to reduce disrespect and abuse, attempts to break down barriers between health workers and clients through regular community facility dialogue and strengthening the health system is a vital factor in inviting more women to health facilities and for improving institutional delivery. It is every woman's right to give birth in a woman centered context with compassionate and respectful care. Provision of woman-centered care in compassionate and a respectful manner needs to be given adequate emphasis to attract more women to health facilities, and to make services more women friendly.

\section{Abbreviations \\ AOR: Adjusted odds ratio; Cl: Confidence interval; MCHIP: Maternal and child health integrated program}

\section{Acknowledgements}

The authors are grateful for the data collectors and study participants.

\section{Funding}

There is no source of funding for this research. All costs were covered by researchers.

Availability of data and materials

The datasets used and/or analyzed during the current study available from the corresponding author on reasonable request.

\section{Authors' contributions}

BW and SZ conceived the study and undertook statistical analysis. BW and SZ supervised the study design and statistical analysis. BW and SZ

contributed to the writing of the manuscript and both authors approved the submitted version of the manuscript.

\section{Ethics approval and consent to participate}

The study protocol was ethically approved by the Ethical Review Board (IRB) of Addis Ababa University College of Health Sciences School of Allied Health Sciences Department of Nursing and Midwifery. Official letter was written to Bahir Dar Town. The study posed a low or not more than a minimal risk to the study participants. Also, the study did not involve any invasive procedures. Accordingly, after the objective of the study was explained verbal informed consent was obtained from all participants over the age of 16 years. In addition to this verbal consent was obtained from a parent on behalf of the participants under the age of 16. Moreover, the confidentiality of information was guaranteed by using code numbers rather than personal identifiers and by keeping the data locked. 


\section{Consent for publication}

Not applicable.

\section{Competing interests}

The authors declare that they have no competing interests.

\section{Publisher's Note}

Springer Nature remains neutral with regard to jurisdictional claims in published maps and institutional affiliations.

\section{Author details}

${ }^{1}$ College of Medicine and Health Sciences, Arba Minch University, Arba Minch, Ethiopia. ${ }^{2}$ Colleges of Medicine and Health Sciences, Debre Tabor University, Debre Tabor, Ethiopia.

Received: 24 January 2018 Accepted: 19 June 2018

Published online: 09 July 2018

\section{References}

1. Council RMCA. White ribbon alliance for safe motherhood.(2011). Respectful maternity care: the universal rights of childbearing women Washington, DC: WRA Retrieved; 2013. p. 1-6.

2. Bowser $\mathrm{D}$, Hill $\mathrm{K}$. Exploring evidence for disrespect and abuse in facility-based childbirth. Boston: USAID-TRAction project, Harvard school of Public Health; 2010.

3. Reis V, Deller B, Catherine Carr C, Smith J. Respectful maternity care. Washington DC: USAID.

4. Moore M, Armbruster D, Graeff J, Copeland R. Assessing the "caring" behaviors of skilled maternity care providers during labor and delivery: experience from Kenya and Bangladesh. The Change Project. 2002.

5. Tunçalp Ö, Were W, MacLennan C, Oladapo O, Gülmezoglu A, Bahl R, et al. Quality of care for pregnant women and newborns-the WHO vision. BJOG Int J Obstet Gynaecol. 2015;122(8):1045-9.

6. Vogel JP, Bohren MA, Tunçalp Ö, Oladapo OT, Adanu RM, Baldé MD, et al. How women are treated during facility-based childbirth: development and validation of measurement tools in four countries-phase 1 formative research study protocol. Reprod Health. 2015:12(1):60

7. Filby A, McConville F, Portela A. What prevents quality midwifery care? A systematic mapping of barriers in low and middle income countries from the provider perspective. PLoS One. 2016;11(5):e0153391.

8. Organization WH. The prevention and elimination of disrespect and abuse during facility-based childbirth: WHO statement. 2014.

9. You D, Hug L, Ejdemyr S, Beise J. Levels and trends in child mortality. Report 2015. Estimates developed by the UN inter-agency Group for Child Mortality Estimation. 2015.

10. WHO. Maternal mortality Fact sheet. from http://wwwwhoint/mediacentre/ factsheets/fs348/en/2014.

11. WHO. Ethiopia Demographic and Health Survey. Maryland: The DHS program ICF Rockville; 2016.

12. Van Lerberghe W. The World Health Report 2005: Make every mother and child count. World Health Organization; 2005.

13. Economic UNDo, Information UNDoP. Millennium Development Goals Report 2009 (Includes the 2009 Progress Chart): United Nations Publications; 2009.

14. Rosen HE, Lynam PF, Carr C, Reis V, Ricca J, Bazant ES, et al. Direct observation of respectful maternity care in five countries: a cross-sectional study of health facilities in east and southern Africa. BMC pregnancy and childbirth. 2015;15(1):306

15. Behruzi R, Hatem M, Fraser W, Goulet L, li M, Misago C. Facilitators and barriers in the humanization of childbirth practice in Japan. BMC Pregnancy and Childbirth. 2010;10(1):25.

16. Bayu H, Adefris M, Amano A, Abuhay M. Pregnant women's preference and factors associated with institutional delivery service utilization in Debra Markos town, north West Ethiopia: a community based follow up study. BMC pregnancy and childbirth. 2015;15(1):15.

17. Asefa A, Bekele D. Status of respectful and non-abusive care during facilitybased childbirth in a hospital and health centers in Addis Ababa, Ethiopia. Reproductive health. 2015;12(1):33.
18. Windau-Melmer T. A guide for advocating for respectful maternity care. 2013.

19. Abuya T, Warren CE, Miller N, Njuki R, Ndwiga C, Maranga A, et al. Exploring the prevalence of disrespect and abuse during childbirth in Kenya. PLoS One. 2015;10(4):e0123606.

20. Okafor II, Ugwu EO, Obi SN. Disrespect and abuse during facility-based childbirth in a low-income country. Int J Gynecol Obstet. 2015;128(2):110-3.

21. Kruk ME, Kujawski S, Mbaruku G, Ramsey K, Moyo W, Freedman LP. Disrespectful and abusive treatment during facility delivery in Tanzania: a facility and community survey. Health Policy Plan. 2014;33(1):e26-33.

\section{Ready to submit your research? Choose BMC and benefit from:}

- fast, convenient online submission

- thorough peer review by experienced researchers in your field

- rapid publication on acceptance

- support for research data, including large and complex data types

- gold Open Access which fosters wider collaboration and increased citations

- maximum visibility for your research: over $100 \mathrm{M}$ website views per year

At BMC, research is always in progress.

Learn more biomedcentral.com/submissions 